\title{
Cathepsin S inhibition suppresses systemic lupus erythematosus and lupus nephritis because cathepsin S is essential for MHC class II-mediated CD4 $\mathrm{T}$ cell and $\mathrm{B}$ cell priming
}

\author{
Khader Valli Rupanagudi, ${ }^{1}$ Onkar P Kulkarni, ${ }^{1}$ Julia Lichtnekert, ${ }^{1}$ \\ Murthy Narayana Darisipudi, ${ }_{1}^{1}$ Shrikant R Mulay, ${ }_{1}^{1}$ Brigitte Schott, ${ }^{2}$ Sabine Gruner, ${ }^{2}$ \\ Wolfgang Haap, ${ }^{2}$ Guido Hartmann, ${ }^{2}$ Hans-Joachim Anders ${ }^{1}$
}

\begin{abstract}
Handling editor Tore K Kvien
- Additional material is published online only. To view please visit the journal online (http://dx.doi.org/10.1136/ annrheumdis-2013-203717).

${ }^{1}$ Medizinische Klinik and Poliklinik IV, Renal Division, Klinikum der Universität München, München, Germany ${ }^{2}$ CV \& Metabolism DTA, Pharma Research and Early Development, Hoffmann La Roche, Basel, Switzerland

\section{Correspondence to} $\mathrm{H}-\mathrm{J}$ Anders, Medizinische Klinik und Poliklinik IV, Klinikum der Universität München-LMU, Ziemssenstr. 1 Munich 80336, Germany; hjanders@med.uni-muenchen. de
\end{abstract}

Received 3 April 2013 Revised 10 September 2013 Accepted 10 November 2013 Published Online First 3 December 2013

\section{ABSTRACT}

Objectives Major histocompatibility complex (MHC) class II-mediated priming of $\mathrm{T}$ and $\mathrm{B}$ lymphocytes is a central element of autoimmunity in systemic lupus erythematosus (SLE) and lupus nephritis. The cysteine protease cathepsin $\mathrm{S}$ degrades the invariant peptide chain during $\mathrm{MHC}$ II assembly with antigenic peptide in antigen-presenting cells; therefore, we hypothesised that cathepsin S inhibition would be therapeutic in SLE. Methods We developed a highly specific small molecule, orally available, cathepsin S antagonist, R05461111, with suitable pharmacodynamic and pharmacokinetic properties that efficiently suppressed antigen-specific T cell and B cell priming in vitro and in vivo.

Results When given to MRL-Fas(lpr) mice with SLE and lupus nephritis, R05461111 significantly reduced the activation of spleen dendritic cells and the subsequent expansion and activation of CD4 T cells and CD4/CD8 double-negative T cells. Cathepsin S inhibition impaired the spatial organisation of germinal centres, suppressed follicular B cell maturation to plasma cells and Ig class switch. This reversed hypergammaglobulinemia and significantly suppressed the plasma levels of numerous $\lg \mathrm{G}$ (but not $\lg \mathrm{M}$ ) autoantibodies below baseline, including anti-dsDNA. This effect was associated with less glomerular IgG deposits, which protected kidneys from lupus nephritis.

Conclusions Together, cathepsin S promotes SLE by driving MHC class II-mediated T and B cell priming, germinal centre formation and B cell maturation towards plasma cells. These afferent immune pathways can be specifically reversed with the cathepsin S antagonist R05461111, which prevents lupus nephritis progression even when given after disease onset. This novel therapeutic strategy could correct a common pathomechanism of SLE and other immune complexrelated autoimmune diseases.

\section{INTRODUCTION}

Systemic lupus erythematosus (SLE) is a systemic autoimmune disease affecting young females by immune complex (IC)-related disease manifestations such as glomerulonephritis (GN), that is, lupus nephritis. ${ }^{12}$ Patients at risk for progressive tissue damage are treated with unselective immunosuppressive drugs such as steroids, cyclophosphamide, mycophenolate mofetil and calcineurin inhibitors, but drug toxicity and lack of efficacy are often associated with poor outcomes. ${ }^{3}$ Novel drugs that interfere with the disease pathomechanisms more specifically are needed to improve lupus management.

Major histocompatibility complex (MHC) class II-mediated priming of (auto-)antigen-specific $\mathrm{T}$ and $\mathrm{B}$ cells is the central element of cellular and humoral (auto-)immunity and has been a target for various innovative treatment approaches. ${ }^{3}$ The presentation of self-antigenic peptides within MHC class II in the context of Toll-like receptor-dependent costimulation activates antigen-specific CD4 T helper cells for their clonal expansion and polarisation into the various CD4 T cell subsets. These cells then activate antigenspecific follicular B cells to undergo clonal expansion inside the germinal centres of the lymphoid follicles. ${ }^{4}$ The germinal centre environment is also needed for driving the somatic hypermutation of activated $\mathrm{B}$ cells, which involves affinity maturation and Ig class switch from immunoregulatory IgM-producing B cells into high affinity and complement-binding IgG-antibody-producing plasma cells. ${ }^{4}$ Subsequently, IC-related pathologies develop either from the deposition of circulating IC or from in situ formation of IC where they trigger tissue inflammation by activating a number of local innate immunity pathways. 56

Cathepsin S (Cat S), a cysteine protease of the papain family, is expressed in lysosomal/endosomal compartments of antigen-presenting cells, such as B cells, macrophages and dendritic cells. ${ }^{7}$ Inside the B cells and dendritic cells, Cat $S$ is the single enzyme that cleaves the Ii p10; a $10 \mathrm{kDa}$ fragment of the MHC-II-bound invariant chain to form 24 amino acid CLIP fragments during the assembly of the MHC class II- $\alpha$ and II- $\beta$ chains with the antigenic peptide in the lysosomal/endosomal compartments. ${ }^{8-14}$ This process contributes to antigen-induced adaptive immunity as demonstrated by vaccinating mice with myelin oligodendrocyte glycoprotein ${ }_{35-55}$ peptide, $^{15}$ bovine type II collagen, ${ }^{15}$ ovalbumin ${ }^{16}$ or $\alpha$-fodrin in Sjögren's syndrome, ${ }^{17}$ even though Cat $S$ was not required for thyroid-stimulating hormone receptorinduced autoimmune thyreoditis. ${ }^{18}$ As, in addition, Cat $S$ degrades autoantigenic peptides favouring 
autoreactive CD4 T cells to escape thymic selection, ${ }^{19}$ there is a robust rationale for Cat $S$ being a mediator of autoimmunity in SLE.

To address this concept, we first characterised Cat S expression in female MRL-(Fas)lpr mice with spontaneous SLE. To study the functional contribution of Cat $S$ and its suitability as a therapeutic target, we developed a specific, orally available, Cat $S$ inhibitor that dose-dependently suppresses the proteolytic activity of murine and human Cat $S$ in vitro and in vivo (table 1). By treating diseased female MRL-(Fas)lpr mice with this compound, we not only demonstrate a non-redundant role of Cat $\mathrm{S}$ for IgG autoantibody production but also identify Cat $\mathrm{S}$ as a therapeutic target for systemic lupus and lupus nephritis.

\section{MATERIALS AND METHODS}

\section{Generation of the Cat S antagonist R05461111}

RO5461111 (CAS 1252637-46-9) was provided by F. HoffmannLa Roche, Ltd., Basel, Switzerland. It is a competitive inhibitor of the active site of Cat $S$, and its nitrile function allows covalent reversible inhibition of Cat $\mathrm{S}$. The synthesis and drug development of RO5461111 has been described in WO 2010121918. Recombinant cathepsins were produced in-house or were purchased from commercial vendors. Enzymatic assays were performed using the fluorogenic substrate (Z-Val-Val-Arg-AMC for human and mouse Cat S, human Cat L \& Cat B, Z-Leu-Arg-AMC for human Cat $\mathrm{K}$ and $\mathrm{Cat} V$ ). The generation of fluorescence over $10 \mathrm{~min}$ was measured using $10 \mu \mathrm{M}$ of substrate and $1 \mathrm{nM}$ of enzyme in the presence of raising concentrations of RO5461111 to determine $\mathrm{IC}_{50}$ values. The cellular activity of RO5461111 was tested in B cell lines of human (RAJI) or mouse (A20) origin by incubating with increasing concentrations of RO5461111 overnight. Protein extracts were prepared for detection of $\mathrm{p} 10$ upregulation by Cat $\mathrm{S}$ inhibition using western blotting. For the determination of in vivo enzyme inhibition activity of Cat S by RO5461111, BALB/c mice were used. After oral dosing of $0.1-100 \mathrm{mg} / \mathrm{kg}$ of RO5461111, mice were sacrificed after $7 \mathrm{~h}$ and spleens harvested. Protein extracts were separated by SDS-gel electrophoresis for the determination of p10 upregulation by Cat $S$ inhibition as described below. A20 cells were plated in RPMI-1640 medium at $3 \times 10^{5}$ cells $/ \mathrm{mL}$ in $100 \mu \mathrm{L} /$ well of a U-bottom 96-well plate. Compounds were added and cells incubated for $1 \mathrm{~h}$ before the addition of ovalbumin to a final concentration of $5 \mathrm{mg} / \mathrm{mL}$ (Sigma-Aldrich). After $16 \mathrm{~h}$, the cells were washed three times with phosphate-buffered saline (PBS) and $2 \times 10^{5}$ DO11.10 $\mathrm{T}$ cell hybridoma cells $/ \mathrm{mL}$ were added. After $24 \mathrm{~h}$, interleukin 2 (IL-2) production was measured as a read out parameter of antigen-specific $\mathrm{T}$ cell activation by Luminex single bead analysis using two anti-IL-2 antibodies (BD, cat. nos.: 554424 and 554426).

\section{Mice and experimental protocol}

Eight-week-old female MRL-Fas(lpr) mice were obtained from Harlan Winkelmann (Borchen, Germany) and kept under pathogen-free and normal housing conditions in a $12 \mathrm{~h}$ light and dark cycle. At the age of 12 weeks, proteinuria and serum creatinine were assessed and only mice with either proteinuria and/or elevated serum creatinine levels were randomised to receive from week 12 either a medicated diet formulated by mixing the Cat $\mathrm{S}$ inhibitor (R05461111, 262.5 mg/kg chow) or standard diet (vehicle) ( $n=15$ in each group). The mice consumed approximately $5 \mathrm{~g}$ food per day (1.31 $\mathrm{mg}$ drug per day) with no difference in food intake or body weight between the two groups. All mice were sacrificed by cervical dislocation at the end of week 20 of age. Blood and urine samples were collected from each mouse at the start of the study (baseline) during the fourth week of the study and at the end of the study period (eighth week). For sheep IgG immunisation study, 8-week-old male C57BL/6 mice were immunised on day 0 subcutaneously (s.c.) in both hind foot pads with $10 \mu \mathrm{g}$ of sheep IgG (Jackson ImmunoResearch Laboratories, Suffolk, UK) in an emulsion containing 50\% (v/v) sterile PBS and $50 \%(\mathrm{v} / \mathrm{v})$ complete Freund's adjuvant (Sigma). On day 7, mice were re-challenged with $10 \mu \mathrm{g}$ of sheep IgG using retro-orbital injection. Ten days after immunisation, the mice were sacrificed by cervical dislocation to collect blood and spleen tissue. All experiments were performed according to German animal protection laws and had been approved by the local government authorities.

\section{Morphological evaluation}

Kidneys and lungs from all mice were fixed in $10 \%$ buffered formalin, processed and embedded in paraffin. Two-micrometer paraffin sections for periodic acid-schiff stains were prepared from lung and kidney tissue samples following routine protocols as described. ${ }^{20}$ The severity of the renal lesions was graded using the indices for activity and chronicity as described for human lupus nephritis. ${ }^{21}$ Cat S, IgG and Mac-2 immunostaining was performed as described using the following primary antibodies: anti-cathepsin $\mathrm{S}$ antibody (abcam, Cambridge, UK), antimouse Mac-2 (Cedarlane Laboratories, Ontario, Canada) and antimouse IgG (Caltag Laboratories). Spleen sections were also stained with IgG (BD Pharmingen) and the lectin peanut agglutinin (PNA) as described, ${ }^{22}$ which binds to immature, proliferating B cells within germinal centres. Immunostaining was performed on frozen sections using antimouse C3c (Nordic Immunological Laboratories). The severity of the peribronchial inflammation was graded semiquantitatively from 0 to 4 as described. ${ }^{23}$ In situ hybridisation was performed using Quantigene ViewRNA ISH Tissue Assay Kit (Affymetrix/Panomics Solutions). The assay uses proprietary chemistry for the target-specific probe sets and branched-DNA signal amplification for detection of specific signal. Specific probe sets for mouse CTSS and EMR1 mRNAs were designed by Affymetrix based on the following sequences: NM 001267695 and NM 021281 for CTSS, and NM 010130 for EMR1. Tissue sections of $4 \mu \mathrm{m}$ prepared from formalin fixed paraffin embedded (FFPE) mouse kidney and spleen tissues were mounted onto microslides (X-tra Adhesive, Leica) and processed according to manufacturer's instructions. Briefly, slides were baked for $1 \mathrm{~h}$ at $60^{\circ} \mathrm{C}$ (Thermobrite, Abbott Molecular) and fixed in 10\% formaldehyde for $1 \mathrm{~h}$ at RT. Deparaffinisation was achieved using Histo-Clear reagent (National Diagnostics). Prehybridisation conditions were found to be optimal with $10 \mathrm{~min}$ of boiling at $95^{\circ} \mathrm{C}$ and $10 \mathrm{~min}$ incubation at $40^{\circ} \mathrm{C}$ with Protease QF diluted $1 / 100 \times$. Target probe set hybridisation (type 6 or type 1 probe sets for blue or red staining, respectively) was carried out for $2 \mathrm{~h}$ at $40^{\circ} \mathrm{C}$. Hybridised probes were amplified using PreAmplifier Mix QT and Amplifier Mix QT oligonucleotides incubating slides at $40^{\circ} \mathrm{C}$ for 25 and $15 \mathrm{~min}$, respectively. Slides were then exposed to Label Probe conjugated with alkaline phosphatase (Label Probe 6-AP or 1-AP for blue or red staining, respectively) for $15 \mathrm{~min}$ at $40^{\circ} \mathrm{C}$ and to Fast Blue or Fast Red substrates at RT for $15 \mathrm{~min}$ or at $40^{\circ} \mathrm{C}$ for $30 \mathrm{~min}$, respectively. When 2-Plex assays were carried out, incubations with Label Probe 6-AP and Fast Blue substrate were carried out before incubations with Label Probe 1-AP and Fast Red substrate. Slides were counterstained with Gill's haematoxylin stain for 5-10 s at RT. In-between each incubation described, slides were washed 2-3 times in washing solution, PBS or water according to the manufacturer's instructions. Imaging was performed under brightfield with a Zeiss microscope equipped with an Axiocam MRC camera. 


\section{Plasma cytokines}

The plasma levels of IL-10 and IL-12p40 were measured using commercial kits from BD (BD Biosciences, San Diego, California, USA) according to the manufacturer's instructions. Plasma levels of IL-2, interferon $\gamma($ IFN- $\gamma)$ and tumour necrosis factor $\alpha$ (TNF- $\alpha)$ were measured using commercial kits from BioLegend (Fell, Germany). Absorbance was read using Tecan Microplate Reader (Biotek, Winooski, Vermont, USA).

\section{Western blotting}

Invariant chain $\mathrm{p} 10$ accumulation was detected in spleen tissue by western blotting. Spleen tissues from vehicle and treated animals were homogenised in RIPA buffer with protease inhibitors. Lysates were electrophoresed and proteins were transferred to PVDF membrane. Membrane was incubated with CD74 primary antibody (BD Pharmingen) and later incubated with antirabbit HRP secondary antibody. The membrane was developed with ECL (GE Healthcare).

\section{Serological analysis}

For the detection of $\operatorname{IgG}$ and its isotypes in the serum, plates were precoated with antimouse IgG, IgG1, IgG2a, IgG2b and IgG3 (Bethyl Laboratories, Montgomery, Texas, USA), and sera were applied at dilutions of $1: 10000$ to 1:50 000. The assay was developed with HRP-labelled goat antimouse IgG, IgG1, IgG2a, IgG2b and IgG3 antibodies (Bethyl Laboratories). A standard curve was derived with purified mouse IgG, IgG1, IgG2a, IgG2b and IgG3 antibodies (Bethyl Laboratories). Serum levels of IgM antibodies were detected using a similar method as described above for $\operatorname{IgG}$ antibodies. Serum levels of IgG and its isotype autoantibodies against dsDNA were determined by specific ELISA as described. ${ }^{24}$ In brief, ELISA plates were coated with poly-L-lysine and then with $1 \mathrm{mg} / \mathrm{mL}$ DNA (purified from mouse tails after proteinase $\mathrm{K}$ digestion and isopropanol precipitation) in SSC buffer. Next, the plates were incubated with 1:2000 diluted serum samples, and the assay was developed with HRP-labelled goat antimouse IgG (Bethyl Laboratories). Serum levels of IgM autoantibodies were detected using a similar method as described above for IgG autoantibodies. Antinuclear antibodies (ANA) were detected by indirect immunofluorescence using HEp-2 cells as described. ${ }^{23}$ For the detection of antibodies specifically against dsDNA, we used Kallestad Crithidia luciliae substrate slides (Bio-Rad). C luciliae is a single-cell organism possessing a giant mitochondrion containing a highly condensed mass of circular dsDNA. This mass of dsDNA, known as the kinetoplast, appears to be free of histones or other mammalian nuclear antigens. It serves as a sensitive and specific substrate for detecting autoantibodies to dsDNA. Plasma levels of rheumatoid factor were estimated by ELISA as described. ${ }^{25}$ For detection of antisheep $\operatorname{IgG}$ in the serum, plates were coated with $100 \mu \mathrm{g} / \mathrm{mL}$ sheep IgG. Mouse antisheep IgG was detected by goat anti-mIgG (Invitrogen, Darmstadt, Germany).

\section{Renal function analysis}

Mouse albumin was estimated in urine samples using a Mouse Albumin ELISA Quantitation set (Bethyl Laboratories). Mouse creatinine was estimated in urine and serum samples using a Creatinine FS kit (DiaSys Diagnostic Systems, Holzheim, Germany). Mouse blood urea nitrogen was estimated in plasma samples using a Urea FS kit (DiaSys Diagnostic Systems). Glomerular filtration rate (GFR) was determined by clearance kinetics of plasma fluorescein isothiocyanate-inulin (Sigma-Aldrich)
Table 1 In vitro enzyme inhibition assay

\begin{tabular}{ll}
\hline Cathepsin & IC $_{50}$ \\
\hline Human cathepsin S & $0.4 \mathrm{~nm}$ \\
Mouse cathepsin S & $0.5 \mathrm{~nm}$ \\
Human cathepsin K & $>25 \mu \mathrm{m}$ \\
Human cathepsin L & $49 \mu \mathrm{m}$ \\
Human cathepsin B & $44 \mu \mathrm{m}$ \\
Human cathepsin V & $1.3 \mu \mathrm{m}$ \\
\hline
\end{tabular}

$5,10,15,20,35,60$ and 90 min after a single intravenous bolus injection. Fluorescence was determined with $485 \mathrm{~nm}$ excitation and read at $535 \mathrm{~nm}$ emission. GFR was calculated based on a twocompartment model using a non-linear regression curve-fitting software (GraphPad Prism; San Diego, California, USA).

\section{T cell activation assay}

Bone marrow derived dendritic cells (DCs) were generated by established protocols. DCs were stimulated with either normal mouse serum or autologous serum for $24 \mathrm{~h}$. CD $4 \mathrm{~T}$ cells were purified from whole splenocytes with anti-CD4 magnetic beads (Miltenyi Biotec). DCs and T cells were cocultured (1:4 ratio) for $48 \mathrm{~h}$, and $\mathrm{T}$ cell activation was measured by flow cytometry using anti-CD69 antibody (BD Biosciences).

\section{Flow cytometry}

Cell suspensions were stained with the following antibodies from BD Pharmingen: antimouse CD3-FITC, CD4-APC, CD8-PerCP, CD69-PE, CD11c-FITC, B220-Alexa Fluor 647, CD138-APC, k Light Chain-PE, IgD-FITC, IgM-PE, CD40-FITC, CD21-FITC, CD23-PE. The following antibodies were procured from Serotec (Oxford, UK): F4/80-allophycocyanin and MHCII-FITC.

\section{Real-time PCR}

Total RNA was isolated from spleen, lung and kidney tissue using PureLink RNA Mini Kit (Invitrogen), and cDNA was synthesised from $1 \mu \mathrm{g}$ total RNA by using random hexamers and SuperScript II Reverse Transcriptase (Invitrogen). SYBR Green I Dye detection system was used for quantitative PCR (qPCR) on LightCycler 480 (Roche Diagnostics). The sequences of the gene-specific primers $(500 \mathrm{nM}$; Metabion, Martinsried, Germany) used are listed in table 3. All reactions were performed in triplicate, and negative controls contained no template DNA as described. ${ }^{26}$ We used $18 \mathrm{~S}$ rRNA as an endogenous control for normalisation. To verify that the primer pairs produced only a single product, a dissociation protocol was added after thermocycling, determining dissociation of the PCR products from $60^{\circ} \mathrm{C}$ to $95^{\circ} \mathrm{C}$. Data were analysed using the comparative threshold cycle $(\Delta \Delta \mathrm{Ct})$ method.

\section{Statistical analysis}

Data are expressed as means \pm SEM. The statistical differences between two groups were performed using a Student $t$ test, and comparison of the three groups was performed using one-way ANOVA. A $p$ value $\leq 0.05$ was considered statistically significant. All statistical calculations were performed using commercially available statistical software GraphPad Prism.

\section{RESULTS}

\section{Cathepsin expression in MRL-Fas(Ipr) mice}

First, we quantified the mRNA expression levels of those cathepsins that are involved in antigen presentation, that is, Cat B, 
Table 2 Primer sequences used for real-time PCR

\begin{tabular}{|c|c|c|}
\hline Gene & $\begin{array}{l}\text { Accession } \\
\text { number }\end{array}$ & Primer sequence \\
\hline CCL2/MCP-1 & NM_011333.3 & $\begin{array}{l}\text { F: } 5^{\prime} \text {-CCTGCTGTTCACAGTTGCC-3' } \\
\text { R: } 5^{\prime} \text {-ATTGGGATCATCTTGCTGGT-3' }\end{array}$ \\
\hline IL-6 & NM_031168 & $\begin{array}{l}\text { F: } 5^{\prime} \text {-TGATGCACTTGCAGAAAACA-3' } \\
\text { R: } 5^{\prime} \text {-ACCAGAGGAATTTTCAATAGGC-3' }\end{array}$ \\
\hline TNF & NM_013693.2 & $\begin{array}{l}\text { F: } 5^{\prime} \text {-CCACCACGCTCTTCTGTCTAC- } 3^{\prime} \\
\text { R: } 5^{\prime} \text {-AGGGTCTGGGCCATAGAACT-3' }\end{array}$ \\
\hline IL-12p35 & NM_001159424.1 & $\begin{array}{l}\text { F: } 5^{\prime} \text {-CTAGACAAGGGCATGCTGGT-3' } \\
\text { R: } 5^{\prime} \text {-GCTTCTCCCACAGGAGGTTT-3'3 }\end{array}$ \\
\hline 18S rRNA & NR_003278 & $\begin{array}{l}\text { F: 5'-GCAATTATTCCCCATGAACG-3' } \\
\text { R: } 5^{\prime} \text {-AGGGCCTCACTAAACCATCC-3' }\end{array}$ \\
\hline IL-10 & NM_021274 & $\begin{array}{l}\text { F: } 5^{\prime} \text {-TGTCAAATTCATTCATGGCCT-3' } \\
\text { R: } 5^{\prime} \text {-ATCGATTTCTCCCCTGTGAA-3' }\end{array}$ \\
\hline IL-1 $\beta$ & NR_003278 & $\begin{array}{l}\text { F: 5'-TTCCTTGTGCAAGTGTCTGAAG-3' } \\
\text { R: 5'-CACTGTCAAAAGGTGGCATTT-3' }\end{array}$ \\
\hline IL-23p19 & NM_031252.2 & $\begin{array}{l}\text { F: 5'-AATAATGTGCCCCGTATCCAGT-3' } \\
\text { R: 5'-GCTCCCCTTTGAAGATGTCAG-3' }\end{array}$ \\
\hline TGF- $\beta 1$ & NM_011577.1 & $\begin{array}{l}\text { F: } 5^{\prime} \text {-CAACCCAGGTCCTTCCTAAA-3' } \\
\text { R: } 5^{\prime} \text {-GGAGAGCCCTGGATACCAAC-3' }\end{array}$ \\
\hline $\begin{array}{l}\text { CXCL12/ } \\
\text { SDF-1 }\end{array}$ & NM_001012477.2 & $\begin{array}{l}\text { F: } 5^{\prime} \text {-GCGCTCTGCATCAGTGAC-3' } \\
\text { R: } 5^{\prime} \text {-TTTCAGATGCTTGACGTTGG-3' }\end{array}$ \\
\hline IFN- $\gamma$ & NM_008337.3 & $\begin{array}{l}\text { F: 5'-ACAGCAAGGCGAAAAAGGAT-3' } \\
\text { R: } 5^{\prime} \text {-TGAGCTCATTGAATGCTTGG-3' }\end{array}$ \\
\hline $\begin{array}{l}\text { CCL5/ } \\
\text { RANTES }\end{array}$ & NM_013653.3 & $\begin{array}{l}\text { F: 5'-CCACTTCTTCTCTGGGTTGG-3' } \\
\text { R: } 5^{\prime} \text {-GTGCCCACGTCAAGGAGTAT-3' }\end{array}$ \\
\hline IL-12p40 & NM_008352.2 & $\begin{array}{l}\text { F: } 5^{\prime} \text {-AGCAGTAGCAGTTCCCCTGA-3' } \\
\text { R: } 5^{\prime} \text {-AGTCCCTTTGGTCCAGTGTG-3' }\end{array}$ \\
\hline April & NM_001159505.1 & $\begin{array}{l}\text { F: } 5^{\prime} \text {-GTTGCTCTTTGGTTGAGTTGGG-3' } \\
\text { R: } 5^{\prime} \text {-GTTGGATCAGTAGTGCGACAGC-3' }\end{array}$ \\
\hline BAFF & NM_033622.1 & $\begin{array}{l}\text { F: } 5^{\prime} \text {-CCACCGTGCCTCTGTTTTTGC- } 3^{\prime} \\
\text { R: } 5^{\prime} \text {-AGCCAACTGGTACAAGGACATCG-3' }\end{array}$ \\
\hline Taci & NM_021349.1 & $\begin{array}{l}\text { F: } 5^{\prime} \text {-GGTCCAGGATTGAGGCTAAGTA-3' } \\
\text { R: 5'-GGAGAGTTTGCTTGTGACCCA-3' }\end{array}$ \\
\hline Cathepsin S & NM_001267695.1 & $\begin{array}{l}\text { F: } 5^{\prime} \text {-AAGCGGTGTCTATGACGACCC-3' } \\
\text { R: } 5^{\prime} \text {-GAGTCCCATAGCCAACCACAAG-3' }\end{array}$ \\
\hline Cathepsin B & NM_007798.3 & $\begin{array}{l}\text { F: } 5^{\prime} \text {-GCAGGCTGGACGCAACTTCTAC-3' } \\
\text { R: } 5^{\prime} \text {-GGTCTCTAATCTGTCCAATGGTCG-3' }\end{array}$ \\
\hline Cathepsin C & NM_009982.4 & $\begin{array}{l}\text { F: } \\
5^{\prime} \text {-GAAGTTGGATACTGCCTACGACGAG-3' } \\
\text { R: } 5^{\prime} \text {-CACATCATGGACCCACCCAGTC-3' }\end{array}$ \\
\hline Cathepsin D & NM_009983.2 & $\begin{array}{l}\text { F: } 5^{\prime} \text {-CGCCTAAGACCACGGAGCCA-3' } \\
\text { R: } 5^{\prime} \text {-ACTTATGGTGGACCCAGCAGGC-3' }\end{array}$ \\
\hline Cathepsin H & NM_007801.2 & $\begin{array}{l}\text { F: } 5^{\prime} \text {-GCTGACCGTGAACGCCATAGA-3' } \\
\text { R: 5' } 5^{\prime} \text {-GCTGTACGTCTTTTGATGCTGTTTCA-3' }\end{array}$ \\
\hline Cathepsin L & NM_009984.3 & $\begin{array}{l}\text { F: } 5^{\prime} \text {-GTGGACTGTTCTCACGCTCA-3' } \\
\text { R: 5'-TATCCACGAACCCTGTGTCA-3' }\end{array}$ \\
\hline Caspase 3 & NM_009810.2 & $\begin{array}{l}\text { F: 5'-TGCTGGTGGGATCAAAGC-3' } \\
\text { R: 5'-TGAATCCACTGAGGTTTTGTTG-3' }\end{array}$ \\
\hline Caspase 7 & NM_007611.2 & $\begin{array}{l}\text { F: } 5^{\prime} \text {-CGGAATGGGACGGACAAAGAT-3' } \\
\text { R: } 5^{\prime} \text {-CTTTCCCGTAATCAGGTCCTC-3' }\end{array}$ \\
\hline Caspase 8 & NM_009812.2 & $\begin{array}{l}\text { F: } 5^{\prime} \text {-TGCTTGGACTACATCCCACAC-3' } \\
\text { R: } 5^{\prime} \text {-TGCAGTCTAGGAAGTTGACCA-3' }\end{array}$ \\
\hline BAD & NM_007522.2 & $\begin{array}{l}\text { F: 5'-AAGTCCGATCCCGGAATCC-3' } \\
\text { R: } 5^{\prime} \text {-GCTCACTCGGCTCAAACTCT-3' }\end{array}$ \\
\hline BID & NM_007544.2 & $\begin{array}{l}\text { F: } 5^{\prime} \text {-GCAAACCTTTGCCTTAGCC- } 3^{\prime} \\
\text { R: } 5^{\prime} \text {-GTGTAGCTCCAAGCACTGCC-3' }\end{array}$ \\
\hline BAX & NM_007527.3 & $\begin{array}{l}\text { F: 5'-TGAAGACAGGGGCCTTTTTG-3' } \\
\text { R: 5'-AATTCGCCGGAGACACTCG-3' }\end{array}$ \\
\hline RIPK1 & NM_009068.3 & $\begin{array}{l}\text { F: } 5^{\prime} \text {-GAAGACAGACCTAGACAGCGGA-3' } \\
\text { R: } 5^{\prime} \text {-CAGTAGCTTCACCACTCGACTG-3' }\end{array}$ \\
\hline RIPK3 & NM_019955.2 & $\begin{array}{l}\text { F: } 5^{\prime} \text {-CTGTCAAGTTATGGCCTACTGGTG-3' } \\
\text { R: } 5^{\prime} \text {-GAACACGACTCCGAACCCTC-3' }\end{array}$ \\
\hline
\end{tabular}

Cat C, Cat D, Cat H, Cat L and Cat S, in kidneys and spleens of 6-, 10- and 14-week-old female MRL-Fas(lpr) mice by real-time PCR. Age-matched and sex-matched MRL wildtype mice served
Table 3 Spleen and lymph node weight in MRL-Fas(lpr) mice

\begin{tabular}{llll}
\hline & Vehicle & R05461111 & p Value by $t$ test \\
\hline Spleen & $1.777 \pm 0.1152$ & $1.505 \pm 0.1111$ & 0.1026 \\
Lymph node & $2.369 \pm 0.2555$ & $1.913 \pm 0.1509$ & 0.1364 \\
\hline
\end{tabular}

as controls. Among these cathepsins, only Cat S, Cat B and Cat $\mathrm{C}$ were induced in kidney at 14 weeks of age (table 2). By contrast, all these cathepsins were induced in spleen starting from 10 weeks of age (see online supplementary figure S1B). In situ hybridisation revealed predominant localisation of Cat $S$ mRNA expression to myeloid antigen-presenting cells, while the Cat $S$ mRNA signal was less dominant in CD20 B cells and clearly absent in CD247 $\mathrm{T}$ cells in spleen, lung and kidney of female MRL-Fas(lpr) mice (see online supplementary figure S2A). Cat S immunostaining was consistent with that cell type-specific expression pattern in spleen and lung, while in kidney epithelial cells of proximal tubules stained positive in the absence of an mRNA signal by in situ hybridisation, implying that Cat $\mathrm{S}$ protein gets reabsorbed from the glomerular filtrate (see online supplementary figure S2B). In the kidney, Cat S positivity was also seen in dendritic cells of the tertiary lymphoid tissue formed in the perivascular area of larger arteries (see online supplementary figure S3). Together, Cat $S$ is expressed in antigen-presenting cells inside and outside of lymphoid tissues.

\section{Pharmacodynamics and pharmacokinetics of R05461111 in mice}

To test the functional contribution of Cat $\mathrm{S}$ in systemic autoimmunity, we used the inhibitor RO5461111 (figure 1A). RO5461111 is a potent and highly selective compound that inhibits human Cat $\mathrm{S}$ with an $\mathrm{IC}_{50}$ of $0.4 \mathrm{nM}$ and murine Cat $\mathrm{S}$ of $0.5 \mathrm{nM}$ (table 3). No submicromolar inhibition was detected on any other of the tested cathepsins. In addition, RO5461111 showed $\leq 30 \%$ inhibition on a diversity panel consisting of nearly 100 receptor binding and enzymatic assays at $10 \mu \mathrm{M}$ concentration (data not shown). The ability of RO5461111 to inhibit Cat $S$ in cells was tested with the lip10 accumulation assay in a human and mouse $\mathrm{B}$ cell line, and a potent induction of lip10 was determined with $\mathrm{EC}_{50}$ of 17 and $8 \mathrm{nM}$, respectively, (data not shown). In addition, RO5461111 dosedependently inhibited ovalbumin presentation of A20 cells to ovalbumin-specific T cells, as quantified by IL- 2 production (see online supplementary figure S4). The acute pharmacodynamic effect of RO5461111 was tested after oral gavage at doses from 0.1 to $100 \mathrm{mg} / \mathrm{kg}$. Splenic induction of $\mathrm{p} 10$ was used as a measure of enzyme inhibition. A strong p10 upregulation was detected with maximal induction at low doses as $1 \mathrm{mg} / \mathrm{kg}$ (figure 1B). Oral administration of RO5461111 by food admix (262 mg/kg of food) to female MRL-(Fas)lpr mice resulted in an exposure dose of $30 \mathrm{mg} / \mathrm{kg}$ and stable plasma levels of RO5461111 at $400-600 \mathrm{ng} / \mathrm{mL}$ over a period of 8 weeks. This was associated with a robust $\mathrm{p} 10$ fragment accumulation in the spleen (figure 1C,D). Furthermore, oral treatment of C57BL/6 mice with RO5461111 suppressed T cell priming and antisheep $\operatorname{IgG}$ upon vaccination with sheep $\operatorname{IgG}$ (figure 1E,F). Together, RO5461111 is a specific small molecule Cat $S$ antagonist with favourable pharmacodynamic and pharmacokinetic profiles to efficiently block Cat $S$ over prolonged periods of time in mice, which has the potential to suppress antigen-induced $B$ and T cell priming. 
A<smiles>Cc1cc(-c2ccc(S(=O)(=O)C3C[C@@H](C(=O)NC4(C#N)CC4)N(C(=O)C4(C(F)(F)F)CC4)C3)c(C(F)(F)F)c2)ccn1</smiles>

C

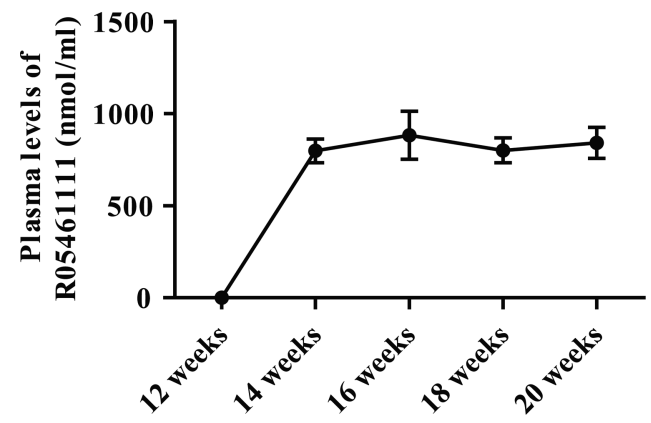

E

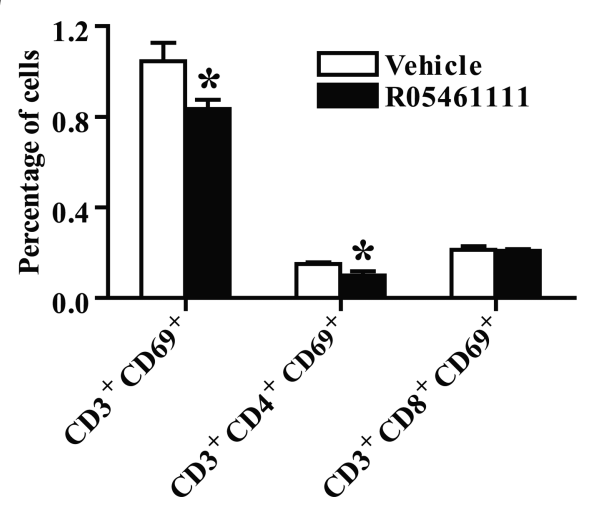

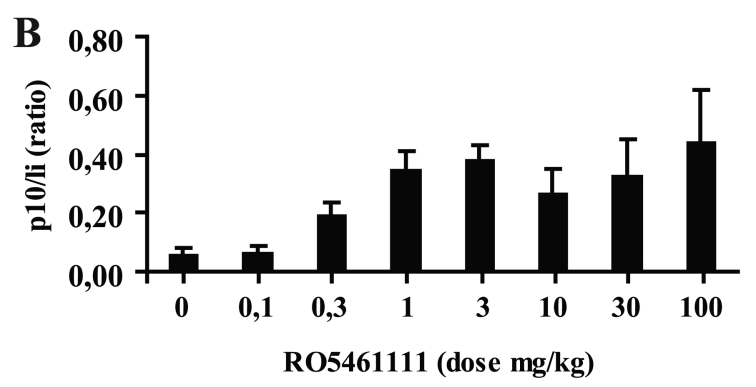

D

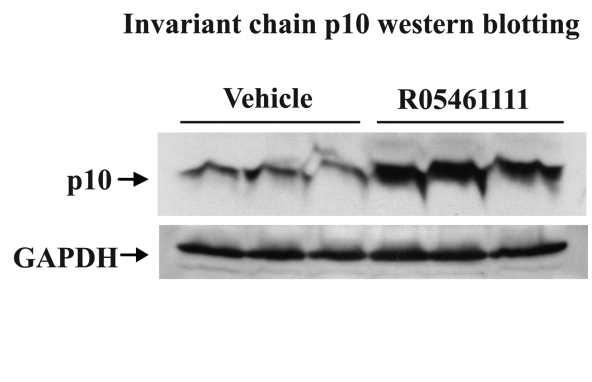

F

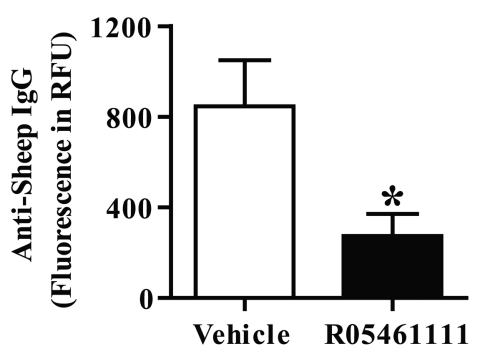

Figure 1 Biochemical and pharmacological profiles of R05461111. (A) Chemical structure of R05461111. (B) Upregulation of invariant chain p10 levels in the spleen tissue was estimated by western blotting upon single-dose feeding of mice with different doses of R05461111 as indicated. (C) Pharmacokinetics of R05461111 in female MRL-Fas(Ipr) mice were determined by during the course of treatment from 12 to 20 weeks of age. Plasma sampling was carried every two weeks, and R05461111 plasma levels were determined by modification of a sandwich hybridisation procedure ( $n=5$ for each time point). (D) Invariant chain p10 levels were estimated from spleen tissue using western blotting. (E) C57BL/6 mice were fed R05461111 during the immunisation with sheep IgG. Spleen suspension flow cytometry analysis of the percentage of total CD3CD69 T cells, CD3CD4CD69 T cells and CD3CD8CD69 T cells. (F) Antisheep IgG antibodies were estimated by ELISA. Data are expressed as means \pm SEM. ${ }^{*} p<0.05$, ${ }^{* *} p<0.01$, versus vehicle group (vehicle $n=15, R 05461111 n=15$ ).

\section{Cat $\mathrm{S}$ blockade with $\mathrm{R} 05461111$ reduces plasma levels of IL-10 and TNF in MRL-(Fas)Ipr mice}

To test the effects of therapeutic Cat $S$ inhibition in autoimmune IC-GN, 12-week-old albuminuric female MRL-Fas(lpr) mice were randomised to two groups that received either normal chow (vehicle) or a food admix with RO5461111. Food intake and weight gain were identical during the following 8 weeks until all mice were sacrificed (data not shown). The same applied to spleen and lymph node weights (see online supplementary table S2). Plasma samples were obtained at baseline (12 weeks of age) and at 4 and 8 weeks of treatment (16 and 20 weeks of age). We first measured IL-10 and IL-12p40 as major dendritic cell-derived cytokines that promote $\mathrm{B}$ and $\mathrm{T}$ cell activation and proliferation, respectively. Cat $\mathrm{S}$ blockade had significantly reduced IL-10 (not IL-12p40) levels but only after 8 weeks of treatment (see online supplementary figure S5A). Therefore, additional cytokines were measured at 8 weeks only. Cat $S$ blockade significantly reduced TNF- $\alpha$ levels, while IL- 2 and IFN- $\gamma$ levels remained unaffected (see online supplementary figure S5B). Thus, Cat S promotes the systemic expression of IL-10 and TNF in MRL-(Fas)lpr mice, which would predict a therapeutic effect on humoral immunity and on tissue inflammation.

Cat S blockade with $\mathrm{R} 05461111$ reduces the activation and expansion of spleen dendritic cells, CD4, double-negative T cells and plasma cells in MRL-(Fas)lpr mice

Next, we performed splenocyte flow cytometry on MRL-(Fas) lpr mice at the end of the study. RO5461111 treatment reduced the percentages of $\mathrm{CD} 11 \mathrm{c} / \mathrm{MHCII}^{+}$and $\mathrm{CD} 11 \mathrm{c} / \mathrm{CD} 40$-activated dendritic cells in MRL-(Fas)lpr mice (figure 2A). This was 
A

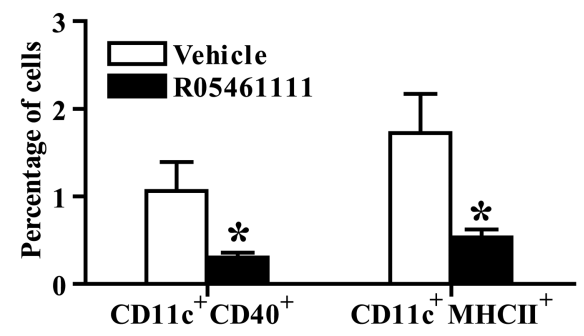

C

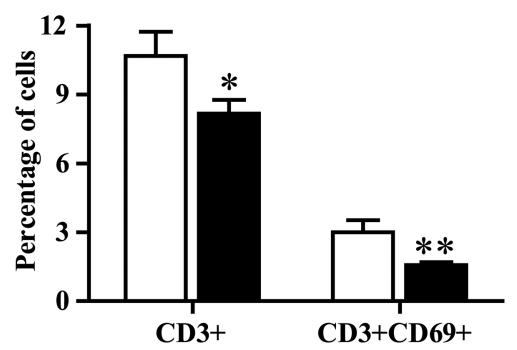

$\mathbf{E}$

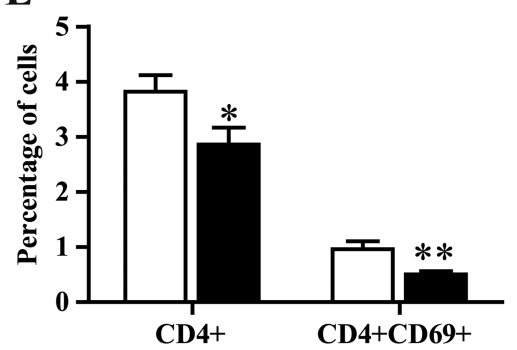

B

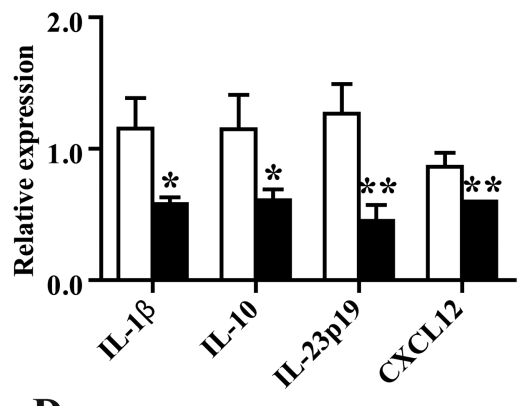

D

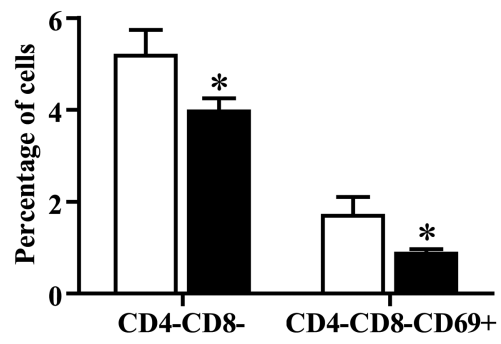

$\mathbf{F}$

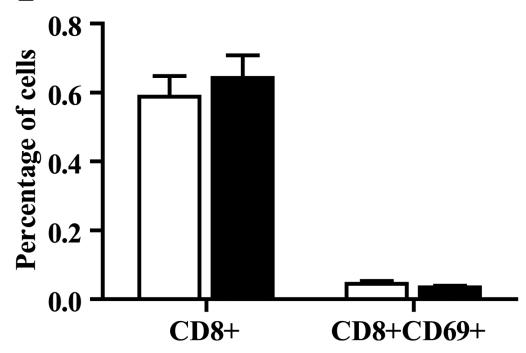

G

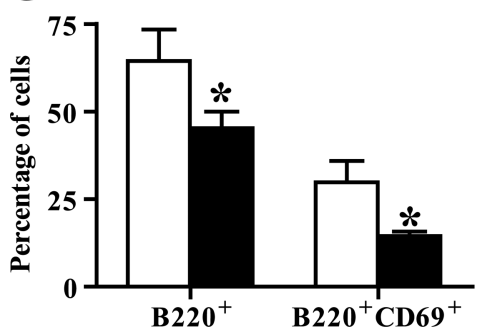

H

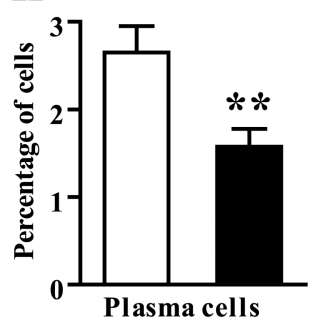

I

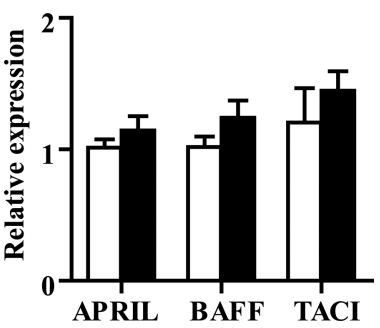

Figure 2 Spleen qPCR and flow cytometry. Spleen cell suspensions were prepared for flow cytometry by using specific antibodies that identify subsets of dendritic cells, T cells, B cells and plasma cells. (A) Fluorescence-activated cell sorting (FACS) analysis of total numbers of CD11c-positive cells that were also positive for the activation markers MHC II or CD40. (B) Splenic mRNA expression levels of IL-1 $\beta$, IL-10, IL-23p19 and CXCL12 were determined by real-time PCR. Data are expressed as mean of the ratio versus the respective $18 \mathrm{~S}$ rRNA level \pm SEM. FACS analysis of the percentage of total CD3 and CD3CD69 T cells (C), percentage of total double-negative and CD69 double-negative T cells (D), percentage of total CD4 and CD4CD69 T cells (E) and percentage of total CD8 and CD8CD69 T cells (F). (G) FACS analysis of the percentage of total spleen B220 ${ }^{+}$and

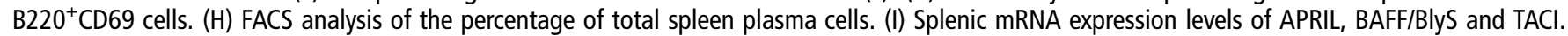
Data are expressed as mean percentages of all splenocytes $\pm \operatorname{SEM}$ ( $n=15$ each treatment group). ${ }^{*} p<0.05,{ }^{* *} p<0.01,{ }^{* * *} p<0.001$, versus vehicle group.

associated with lower spleen mRNA expression levels for IL-1 $\beta$, IL-10, IL-23p19 and CXCL12, while the levels of IL-6, IL-12p35, IFN- $\gamma$, TGF- $\beta$, CCL2 and CCL5 were not reduced (figure 2B and see online supplementary figure S6). Less spleen dendritic cell activation and cytokine expression may affect $\mathrm{T}$ cell priming, which is anyway triggered by circulating lupus autoantigens in these mice (see online supplementary figure S7A). RO5461111 significantly reduced the amount of spleen CD3 cells as well as activated (CD69) CD3 cells (figure 2C). RO5461111 treatment significantly reduced CD4 cells and CD4/CD8 double-negative T cells as well as activated (CD69)
CD4 $\mathrm{T}$ cells and (CD69) CD4/CD8 double-negative T cells (figure 2D,E). In contrast to RO5461111's effect on CD4 cells, it did not affect the amount and activation stage of CD8 T cells (figure 2F). Dendritic cells and activated $\mathrm{T}$ helper cells both regulate antigen-specific $\mathrm{B}$ cell and plasma cell responses. The inhibitor significantly reduced $\mathrm{B} 220^{+} \mathrm{CD} 69$-activated $\mathrm{B}$ cells while the expression of APRIL, BAFF and TACI remained unaffected (figure 2G-I). Cat S blockade significantly reduced the spleen mRNA levels of several cell death-related markers such as RIPK1, caspase 3, caspase 7, BID and BAX (see online supplementary figure S7B). However, RO5461111 treatment 


\section{Basic and translational research}

significantly reduced the numbers of CD138 $\mathrm{k}$ Light chain ${ }^{+}$ plasma cells (figure $2 \mathrm{H}$ ). Together, Cat $S$ promotes the activation and expansion of spleen dendritic cells, CD4 T cells, B cells and plasma cells in MRL-(Fas)lpr mice, a process blocked by RO5461111.

\section{Cat S blockade with R05461111disrupts germinal centres in MRL-(Fas)Ipr mice}

Systemic autoimmunity depends on the complex interaction of myeloid cells and lymphocytes to promote the clonal selection of autoreactive lymphocytes as well as Ig class switch and affinity maturation of autoantibodies. ${ }^{1} 427$ These processes involve $\mathrm{PNA}+$ follicular B cells and takes place in the germinal centres of the lymphoid tissue. ${ }^{4}$ Vice versa, disruption of germinal centre formation counteracts autoimmunity. ${ }^{4}$ PNA revealed that Cat $S$ inhibition altered the distribution of follicular B cells away from the germinal centre in lymphoid follicles to the perifollicular area in spleens of MRL-(Fas)lpr mice (see online supplementary figure S8), implying that Cat $\mathrm{S}$ inhibition disrupted the spatial organisation of germinal centres. This findings was consistent with a RO5461111-related significant reduction of spleen CXCL12 mRNA expression that is required for germinal centre formation (figure $2 \mathrm{~B}$ ). Together, Cat $\mathrm{S}$ is required for germinal centre formation in MRL-(Fas)lpr mice, which can be suppressed by RO5461111.

\section{Cat S blockade with R05461111 reduces hypergammaglobulinemia and lupus autoantibody production in MRL-(Fas)Ipr mice}

B cell maturation and plasma cell expansion account for hypergammaglobulinemia and the production of high-affinity IgG autoantibodies in SLE. In vehicle-treated MRL-(Fas)lpr mice, total IgG plasma levels increased from week 12 to 20 of age, which mostly related to $\operatorname{IgG} 1$ and $\operatorname{IgG} 2 \mathrm{a}$ (figure $3 \mathrm{~A}$ ). RO5461111 treatment significantly reduced total IgG, IgG1, IgG2a and IgG2b levels already after 4 weeks of treatment, but there was a progressive decline of especially IgG1 and IgG2a below baseline along treatment (figure 3A). In contrast, IgG3 and $\operatorname{IgM}$ levels remained unaffected (figure 3A,B). The 20-week-old MRL-(Fas)lpr mice displayed strong positivity for ANA in a diffuse nuclear staining pattern consistent with the presence of anti-DNA antibodies (figure 4A). This was validated
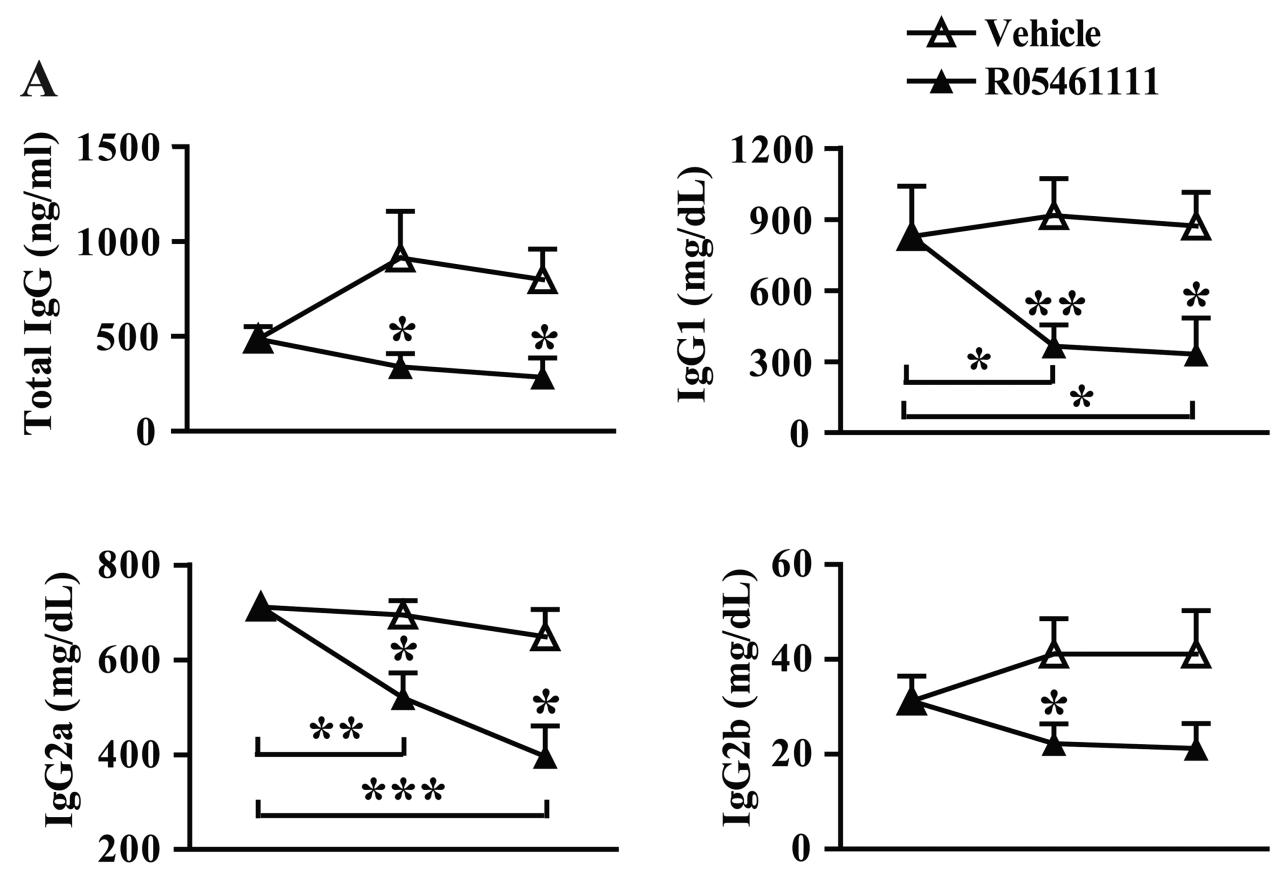

\section{B}
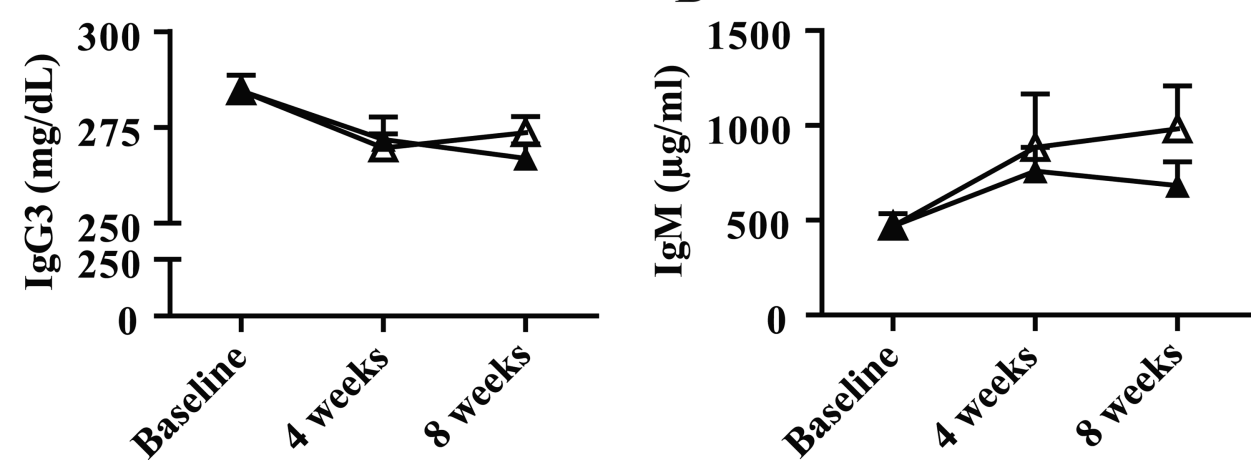

Figure 3 R05461111 reduces IgG antibodies in MRL-Fas(Ipr) mice. (A) Plasma levels of total IgG and its isotypes IgG1, IgG2a, IgG2b and IgG3 were determined by ELISA. (B) Plasma levels of IgM antibodies were determined by ELISA. Data are expressed as means \pm SEM ( $\mathrm{n}=15$ each treatment group). ${ }^{*} p<0.05,{ }^{* *} p<0.01$, versus vehicle group. 
Vehicle

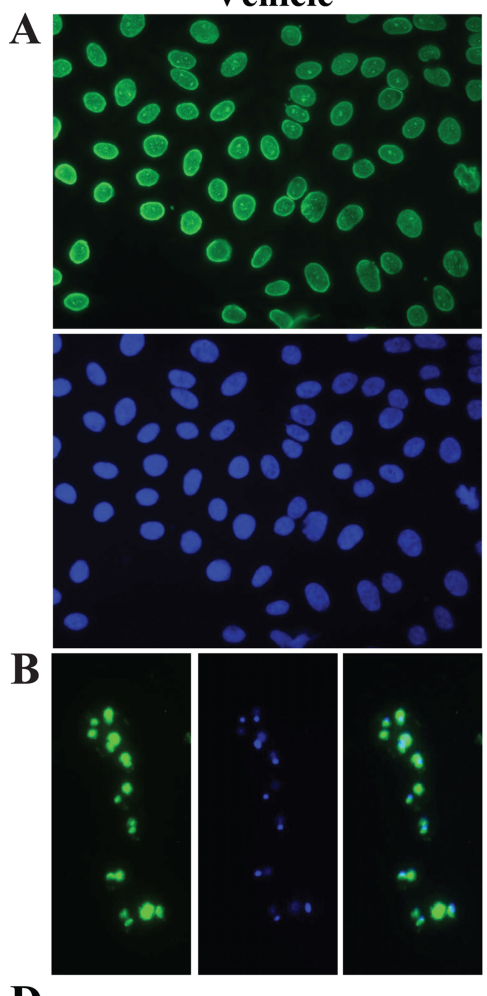

D
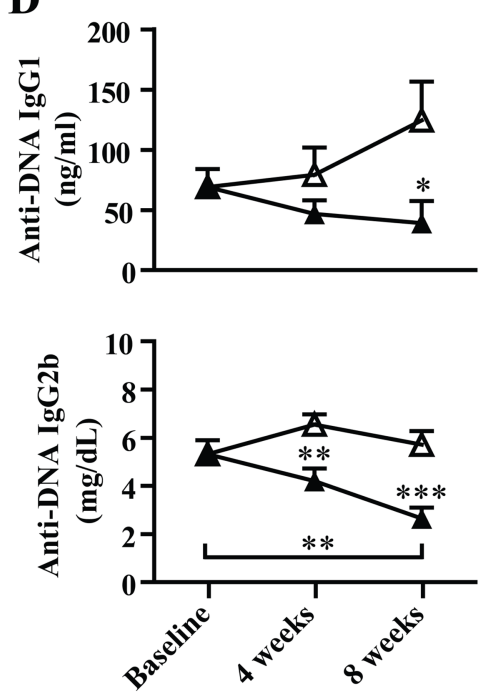

\section{R05461111}

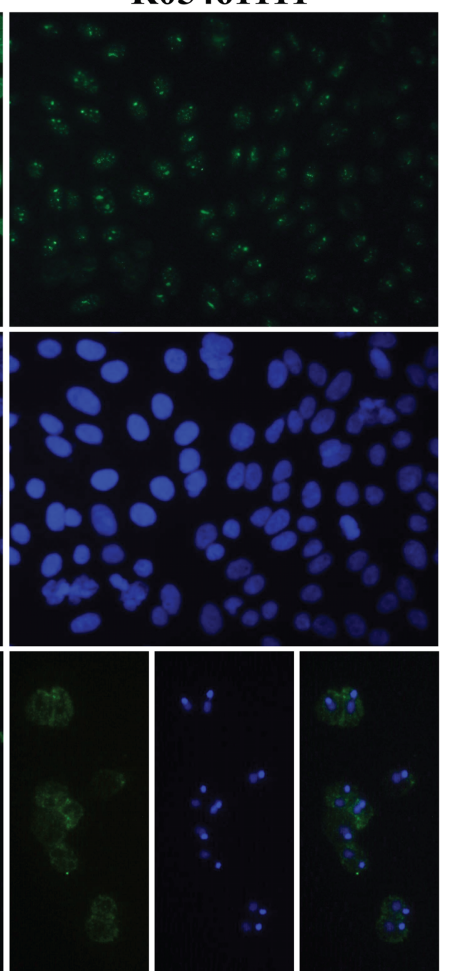

$\mathbf{C}$
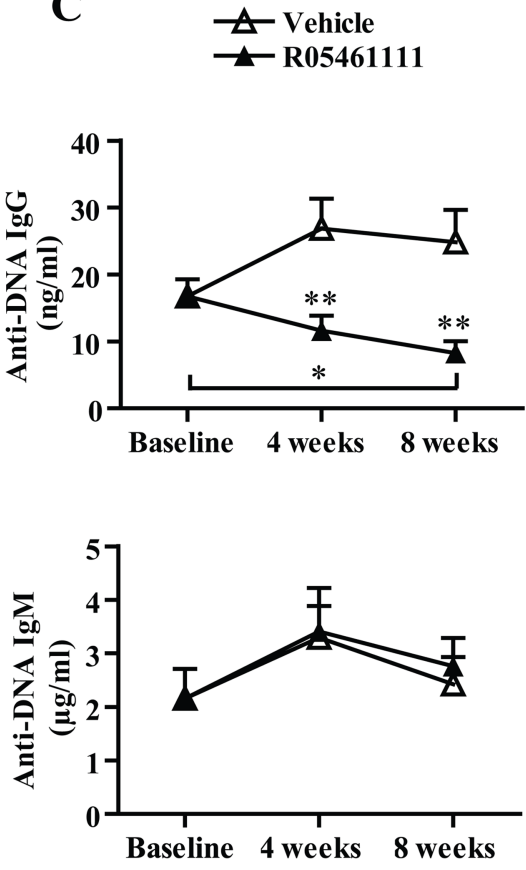

$\mathbf{E}$
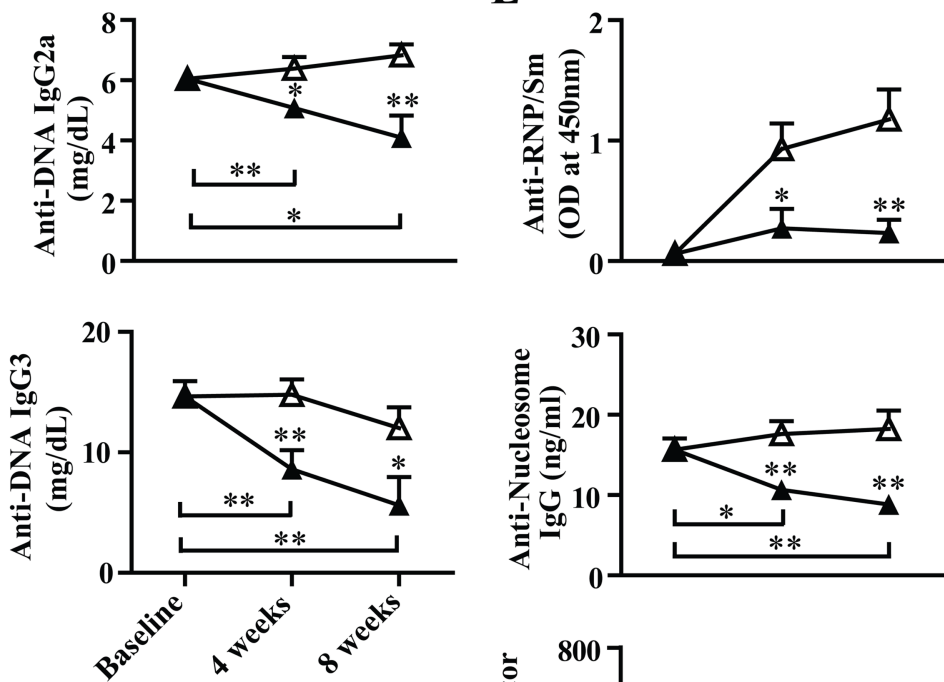

Figure 4 R05461111 reduces autoantibodies in MRL-Fas(lpr) mice. (A) Antinuclear antibodies (ANA) staining patterns on Hep2 human epithelial cells for serum derived from vehicle-treated and R05461111-treated MRL-Fas(Ipr) mice at 1:200 dilution. (B) Crithidia luciliae slides were incubated with 1:50 diluted plasma of 20-week-old mice from both treatment groups, and autoantibody binding to the flagellate's kinetoplast was detected using an FITC-labelled goat antimouse IgG. Images on the left show anti-dsDNA IgG in green, and staining the kinetoplast DNA itself with DAPI shown in blue is shown in the middle. The merged pictures are shown on the right side, demonstrating that FITC positivity matches with the kinetoplast at the flagella pole of $C$ luciliae. (C) Plasma levels of anti-dsDNA IgG and IgM antibodies were determined by ELISA. (D) Plasma levels of $\lg$ isotypes such as $\lg G 1$, IgG2a, IgG2b and IgG3 against ds-DNA were determined by ELISA. (E) Plasma levels of anti-RNP/Sm, antinucleosome antibodies and rheumatoid factor were determined by ELISA. Data are expressed as means $\pm S E M\left(n=15\right.$ each treatment group,). * $p<0.05,{ }^{* *} p<0.01$, $* * * p<0.001$ versus vehicle. 
by kinetoplast staining of the monocellular organism $C$ luciliae that contains pure double-stranded (ds) DNA (figure 4B). Cat $S$ blockade with RO5461111 drastically reduced ANA as well as C luciliae kinetoplast positivity (figure 4A,B). Quantitative assessment of anti-dsDNA IgG and IgM during the treatment period confirmed that RO5461111 treatment reduced anti-dsDNA IgG but not IgM plasma levels (figure 4C). This effect on Ig class switch related to all subclasses of IgG (figure 4D). It is of note that Cat $S$ blockade leads to a progressive decline below baseline levels during the treatment period (figure 4D), suggesting that Cat $S$ is needed to maintain autoantibody production in existing clones of autoreactive plasma cells. RO5461111 treatment also significantly reduced the plasma levels of antinucleosome $\operatorname{IgG}$, anti-smRNP $\operatorname{IgG}$ and rheumatoid factor in MRL-(Fas)lpr mice, while the respective IgM autoantibodies remains unaffected (figure $4 \mathrm{E}$ and see online supplementary figure S9). Thus, Cat S drives hypergammaglobulinemia and the production of antinuclear IgG autoantibody production in MRL-(Fas)lpr mice, a process that can be reversed by RO5461111.

\section{Cat S blockade with R05461111 improves lupus nephritis in MRL-(Fas)Ipr mice}

Lupus nephritis develops from intrarenal IC deposition and local complement activation. ${ }^{3}$ Vehicle-treated 20 -week-old female MRL-Fas(lpr) mice displayed strong intraglomerular IgG and complement C3c deposits, which was associated with diffuse mesangial matrix expansion, profound mesangial cell proliferation and focal segmental glomerulosclerosis (figure 5A). Cellular crescents and global glomerulosclerosis were often seen. Most animals revealed profound tubulointerstitial inflammation as characterised by periglomerular and diffuse interstitial leucocyte infiltrates, tubular atrophy and intraluminal cast formation. Cat S blockade with RO5461111 significantly reduced glomerular $\operatorname{IgG}$ and $\mathrm{C} 3 \mathrm{c}$ deposits (figure $5 \mathrm{~B}$ ) and the glomerular as well as the tubulointerstitial immunopathology as quantified by the lupus nephritis activity index that encompasses glomerular cell proliferation, matrix deposition, leucocyte infiltration, focal necrosis, crescent formation and tubulointerstitial inflammation. Treatment with RO5461111suppressed lupus nephritis as documented by a significant reduction of the nephritis chronicity index that encompasses glomerular sclerosis, fibrous crescents, tubular fibrosis and interstitial fibrosis (figure 5C). This improvement of renal structure was associated with a significant reduction of proteinuria and serum creatinine levels after 8 weeks of treatment (figure 5D,E). GFR, as assessed by FITC-inulin clearance kinetics at the end of the study, was severely impaired in vehicle-treated MRL-Fas(lpr) mice but significantly increased upon RO5461111 treatment (figure 5F). These effects were associated with significantly reduced mRNA expression levels of IL-1 $\beta$, IL-6, IL-10 and IL-12p35, while IFN- $\gamma$ and TGF- $\beta 1$ remained unaffected (see online supplementary figure S10A). However, RO5461111 significantly reduced the number of glomerular $\mathrm{Mac}-2^{+}$macrophages and of activated dendritic cells (see online supplementary figure S10B,D,E). Fluorescence-activated cell sorting (FACS) analysis of kidney $\mathrm{F} 4 / 80^{+}$macrophages has shown a trend towards less macrophages in the kidneys of R05461111-treated mice (see online supplementary figure $\mathrm{S} 10 \mathrm{C})$. Thus, Cat $\mathrm{S}$ contributes to the progression of lupus nephritis in MRL-Fas(lpr) mice, a process that can be prevented by RO5461111.
Cat S blockade with R05461111 reduces lung inflammation in MRL-(Fas)Ipr mice

The lung is another organ frequently affected by systemic autoimmunity in MRL-Fas(lpr) mice. Vehicle-treated MRL-Fas(lpr) mice developed prominent peribronchial immune cell infiltrates that compressed and destroyed lung tissue (figure 6A,B). Such infiltrates were significantly decreased in 20-week-old RO5461111-treated MRL-Fas(lpr) mice together with less mRNA expression levels of IL-6, IL-12p40 and CCL2 (figure 6C), and lower numbers of $\mathrm{Mac}-2^{+}$macrophages (figure $6 \mathrm{D}$ ). Thus, Cat $\mathrm{S}$ also promotes pulmonary inflammation and damage in MRL-Fas (lpr) mice. Obviously, late onset of RO5461111 therapy abrogates autoantibody production and IC disease in MRL-Fas(lpr) mice.

\section{DISCUSSION}

The central role of MHC class II-mediated T and B cell priming for autoimmunity and the non-redundant role of Cat $S$ in peptide loading and MHC class II assembly prompted us to speculate that Cat $S$ could be a potential therapeutic target for SLE. Humoral autoimmunity develops from the presentation of autoantigens in the context of costimulation, followed by an expansion of autoreactive lymphocytes and the clonal selection of high-affinity IgG autoantibody-producing plasma cells, a process that takes place in the germinal centres of lymphoid follicles. ${ }^{4}$ Our data confirm previously published reports that Cat $S$ inhibition interferes with all of these processes upon vaccination with foreign or self-antigens, ${ }^{10}{ }^{19}$ most likely by limiting Ii-dependent peptide loading into MHC class II. The novel aspects of our study are threefold. First, here we report a novel Cat $S$ antagonist that is potentially suitable for therapy in humans. Second, we first document the contribution of Cat $S$ in lupus-like spontaneous systemic autoimmunity and antinuclear antibody production. This process specifically involves priming of CD4 T cell subsets (but not CD8 T cells) and affinity maturation towards IgG autoantibody-producing plasma cells within germinal centres. Third, Cat $S$ blockade initiated as late upon 'clinically' detectable signs of lupus nephritis, such as proteinuria and/or elevated serum creatinine, was effective in suppressing hypergammaglobulinemia and autoantibody production below baseline and in preventing lupus nephritis progression.

Cat $S$ inhibition with the novel, orally available, and highly selective Cat S inhibitor RO5461111 was effective in vivo and had profound effects on the lupus-like systemic autoimmunity that spontaneously develops in MRL-Fas(lpr) mice. The most striking therapeutic effect was the suppression of $\mathrm{IgG}$ but not IgM (auto-)antibody production, which was consistent for all ANA specificities tested. This effect on Ig class switch implies that Cat $S$ contributes to the affinity maturation of the respective antibody-producing cells, which was consistent with a significant suppression of spleen plasma cells upon Cat $S$ inhibition. Affinity maturation takes place in the germinal centres of lymphoid follicles and requires an orchestrated interaction of antigenpresenting cells and lymphocytes such as follicular dendritic cells, follicular B cells and antigen-specific CD4 T helper cells. ${ }^{4}$ Cat $\mathrm{S}$ inhibition disrupted the typical spatial organisation of the germinal centres in MRL-Fas(lpr) mice, as was reported by previous vaccination studies using Cat $\mathrm{S}$-deficient mice or less selective Cat $\mathrm{S}$ antagonists. ${ }^{8} 1522$ Obviously, compromising appropriate MHC class II assembly is sufficient to impair germinal centre formation, for example, by suppressing CXCL12 expression, a factor needed for the spatial organisation of follicular B cells to the dark zone of germinal centres and their maturation towards plasma cells that produce high-affinity IgG 
A
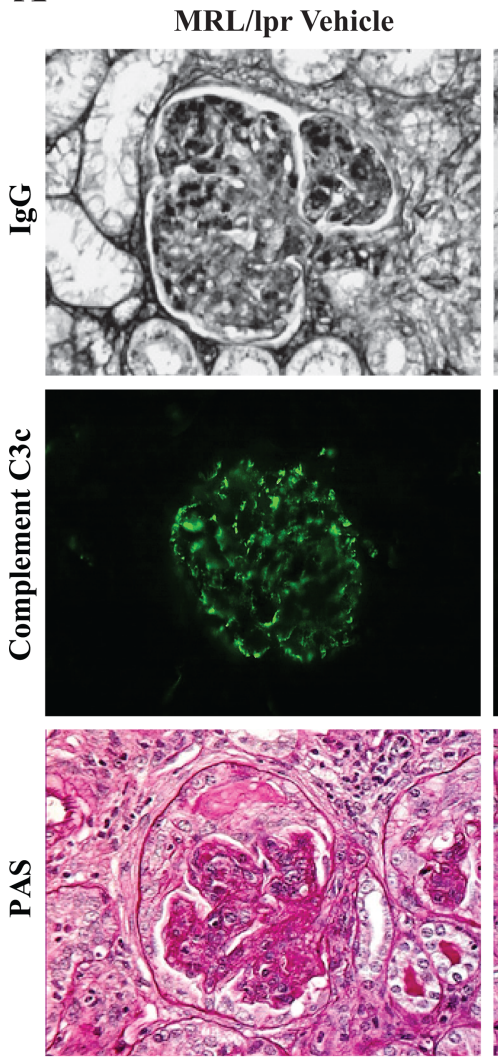

D

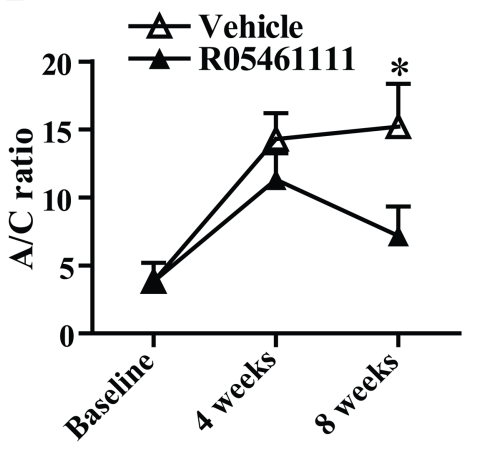

MRL/lpr R05461111
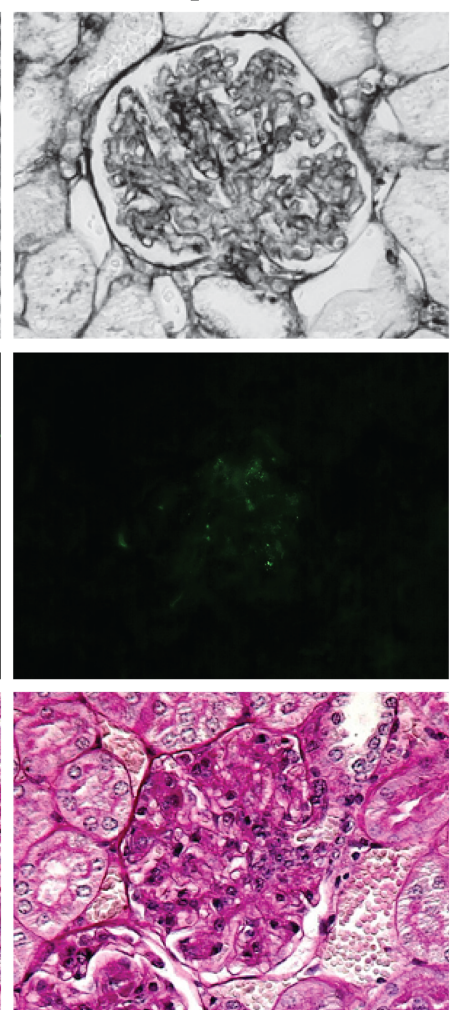

$\mathbf{E}$

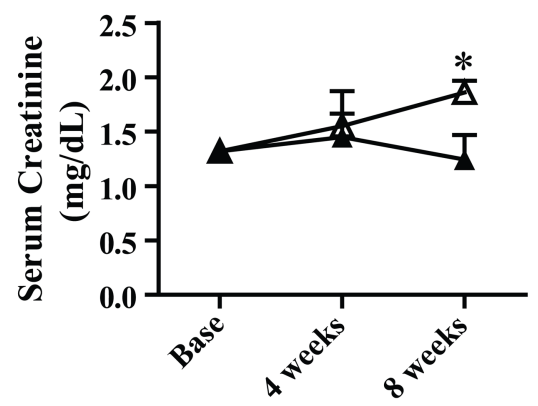

B
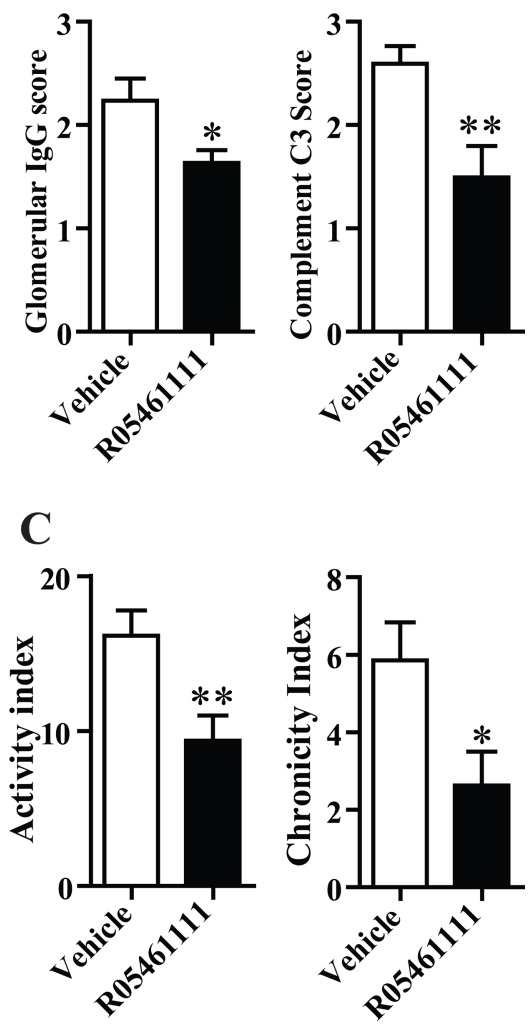

$\mathbf{F}$

Figure 5 R05461111 suppresses renal pathology in MRL-Fas(lpr) mice. (A) Renal sections of 20-week-old MRL-Fas(lpr) mice were stained with antibodies for IgG and complement C3c as indicated. Note that inhibitor-treated mice show less glomerular lgG and C3c deposits. Renal sections of 20-week-old MRL-Fas(Ipr) mice were stained with periodic acid-schiff (PAS). Representative PAS staining kidney sections showed glomerular damage in vehicle-treated mice compared with inhibitor-treated mice. Images are representative for 15 mice in each treatment group. Magnification, $\times 400$ or $\times 200$. (B) Quantitative measures of lupus nephritis in MRL-Fas(Ipr) mice. (B) Glomerular IgG and complement C3c deposition was compared between vehicle-treated and inhibitor-treated groups (score ranging from 0 to 3 ). (C) The lupus nephritis disease activity index (scores ranging from 0 to 24) and the lupus nephritis chronicity index (scores ranging from 0 to 12) were determined as markers of kidney damage in lupus nephritis. Renal functional parameters like proteinuria (D), plasma creatinine (E) and glomerular filtration rate (F) were determined from 15 mice in each treatment group at 20 weeks of age. Data are expressed as means \pm SEM. ${ }^{*} p<0.05,{ }^{*} p<0.01$, versus vehicle group (vehicle $n=15, R 05461111$ $n=15)$.

autoantibodies. $^{28} 29$ By contrast, Cat $\mathrm{S}$ is not involved in peptide loading to MHC class I; hence, Cat $S$ inhibition did not affect CD8 T cells in MRL-Fas(lpr) mice. This implies that therapeutic Cat $\mathrm{S}$ inhibition spares MHC I-mediated and CD8 T cellmediated immunity, which should reduce the risks of therapy-associated infections as compared with global immunosuppressants such as steroids, cyclophosphamide or mycophenolate mofetil. Of note, we did not observe any infectious complications in the mice studied with the Cat $S$ inhibitor.
We designed our study also to test the therapeutic potential of Cat S inhibition; hence, treatment was initiated not before 'clinically' detectable signs of autoimmune tissue injury, such as proteinuria and/or elevated serum creatinine, became evident. It is of note that Cat $\mathrm{S}$ inhibition suppressed hypergammaglobulinemia and autoantibody production below the baseline levels, consistent with a reversal of the underlying systemic autoimmune process. ${ }^{30}$ However, at the tissue level, Cat $S$ inhibition was effective only in terms of preventing a further increase in serum 
A

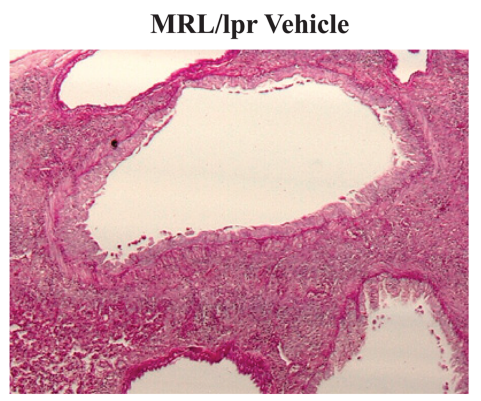

C

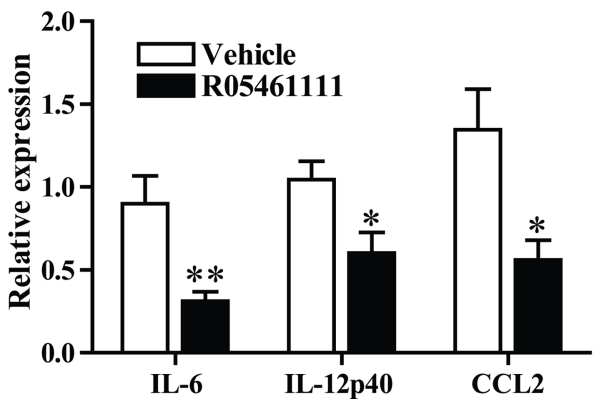

B
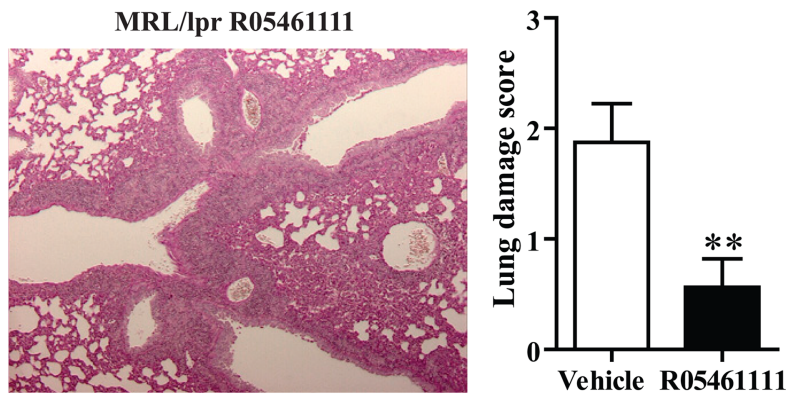

D

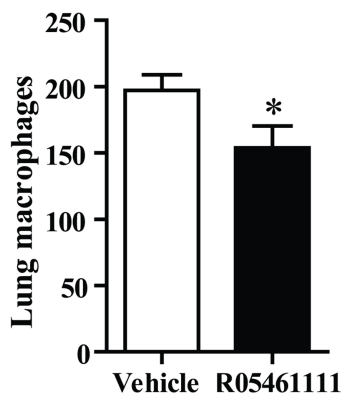

Figure 6 Cathepsin S inhibitor R05461111 improves lung disease in MRL-Fas(Ipr) mice. (A) Lung sections of 20-week-old MRL-Fas(lpr) mice of both groups were stained with PAS. Note the peribronchial and perivascular lymphocyte infiltrates were less in R05461111 mice compared with vehicle mice. Images are representative for 15 mice in each treatment group. Original magnification, $\times 100$. (B) Morphometry was used to quantify the peribronchiolar and perivascular inflammation by using a score ranging from 0 to 3 and scored semiquantitatively as described in the 'Methods' section. (C) Lung mRNA expressions of IL-6, IL-12p40 and CCL2 in MRL-Fas(|pr) mice were determined by quantitative real-time PCR. (D)

Quantification of lung macrophages. Data represent mean scores $\pm S E M$. ${ }^{*} p<0.05$, ${ }^{* *} p<0.01$, versus vehicle group. (vehicle $n=15, R 05461111 n=15$ ).

creatinine, which implies a stabilisation of renal function and not a reversal of tissue remodelling. Even when admitting that the reversal of tissue remodelling may take more time than we studied here, our data would favour to initiate Cat $\mathrm{S}$ blockade at an early stage of SLE to normalise aberrant immunity and to prevent disease progression.

In summary, Cat $S$ is a non-redundant mediator of SLE because it is required for the assembly of MHC class II molecules with autoantigenic peptides. Interfering with this process disturbs germinal centre formation, that is, the expansion and activation of CD4 T cells, as well as the activation and maturation of autoreactive B cells and subsequent production of high-affinity IgG autoantibodies. Vice versa, therapeutic Cat $S$ inhibition reverts the aberrant autoimmune response and protects from progressive lupus nephritis. This therapeutic intervention that spares CD8 T cell-mediated adaptive immunity holds the potential to avoid the unfavourable side effects of unselective immunosuppressive drugs currently used for the treatment of SLE.

Acknowledgements The authors thank Dan Draganovic and Jana Mandelbaum for their excellent technical assistance.

Contributors All authors contributed to the manuscript.

Competing interests BS, SG, WH and GH are employees of F. Hoffmann-La Roche, Ltd., Basel, Switzerland.

Provenance and peer review Not commissioned; externally peer reviewed.

\section{REFERENCES}

1 Rahman A, Isenberg DA. Systemic Lupus Erythematosus. N Eng J Med 2008:358:929-39.

2 Lech M, Anders HJ. The pathogenesis of lupus nephritis. J Am Soc Nephrol 2013:24:1357-66.

3 Kulkarni OP, Anders $\mathrm{H}-\mathrm{J}$. Lupus nephritis. How latest insights into its pathogenesis promote novel therapies. Curr Opin Rheumatol 2012;24:457-65.
4 Victora GD, Nussenzweig MC. Germinal centers. Annu Rev Immunol 2012;30:429-57.

5 Glassock RJ. Human idiopathic membranous nephropathy-a mystery solved? N Engl J Med 2009;361:81-3.

6 Anders HJ. Toll-like receptors and danger signaling in kidney injury. J Am Soc Nephrol 2010;21:1270-4.

7 Gupta S, Singh RK, Dastidar S, et al. Cysteine cathepsin S as an immunomodulatory target: present and future trends. Expert Opin Ther Targets 2008;12:291-9.

8 Riese RJ, Wolf PR, Brömme D, et al. Essential role for Cathepsin S in MHC Class II associated invariant chain processing and peptide loading. Immunity 1996;4:357-66.

9 Driessen C, Bryant RAR, Lennon-Duménil A-M, et al. Cathepsin S controls the trafficking and maturation of Mhc Class II molecules in dendritic cells. J Cell Biol 1999;147:775-90.

10 Germain RN. MHC-dependent antigen processing and peptide presentation: providing ligands for T lymphocyte activation. Cell 1994;76:287-99.

11 Roche PA, Marks MS, Cresswell PJ. Formation of a nine-subunit complex by HLA class II glycoproteins and the invariant chain. Nature 1991;354:392-4.

12 Riese RJ, Mitchell RN, Villadangos JA, et al. Cathepsin S activity regulates antigen presentation and immunity. J Clin Inves 1998;101:2351-63.

13 Blum JS, Cresswell P. Role for intracellular proteases in the processing and transport of class II HLA antigens. Proc Natl Acad Sci 1988;85:3975-9.

14 Shi GP, Munger JS, Meara JP, et al. Molecular cloning and expression of human alveolar macrophage cathepsin $S$, an elastinolytic cysteine protease. I Biol Chem 1992;267:7258-62.

15 Baugh M, Black D, Westwood P, et al. Therapeutic dosing of an orally active, selective cathepsin $S$ inhibitor suppresses disease in models of autoimmunity. J Autoimmun 2011;36:201-9.

16 Deschamps K, Cromlish W, Weicker S, et al. Genetic and pharmacological evaluation of Cathepsin S in a mouse model of asthma. Am J Respir Cell Mol Biol 2011;45:81-7.

17 Saegusa K, Ishimaru N, Yanagi K, et al. Cathepsin S inhibitor prevents autoantigen presentation and autoimmunity. J Clin Invest 2002;110:361-9.

18 Kala M, Chen CR, McLachlan SM, et al. Cathepsin S is not crucial to TSHR processing and presentation in a murine model of Graves' disease. Immunology 2005;116:532-40.

19 Stoeckle C, Quecke P, Rückrich T, et al. Cathepsin S dominates autoantigen processing in human thymic dendritic cells. J Autoimmun 2012;38:332-43.

20 Patole PS, Pawar RD, Lichtnekert J, et al. Coactivation of Toll-like receptor-3 and -7 in immune complex glomerulonephritis. J Autoimmun 2007;29:52-9.

21 Austin HA III, Muenz LR, Joyce KM, et al. Diffuse proliferative lupus nephritis: identification of specific pathologic features affecting renal outcome. Kidney Int 1984;25:689-95. 
22 Shi G-P, Villadangos JA, Dranoff G, et al. Cathepsin S required for normal MHC Class II peptide loading and germinal center development. Immunity 1999;10:197-206.

23 Allam R, Pawar RD, Kulkarni OP, et al. Viral 5'-triphosphate RNA and non-CpG DNA aggravate autoimmunity and lupus nephritis via distinct TLR-independent immune responses. Eur J Immunol 2008;38:3487-98.

24 Kulkarni O, Pawar RD, Purschke W, et al. Spiegelmer Inhibition of CCL2/MCP-1 Ameliorates Lupus Nephritis in MRL-(Fas)|pr Mice. J Am Soc Nephrol 2007; $18: 2350-8$

25 Lech M, Skuginna V, Kulkarni OP, et al. Lack of SIGIRR/TIR8 aggravates hydrocarbon oil-induced lupus nephritis. J Pathol 2010;220:596-607.
26 Lech M, Susanti HE, Rommele C, et al. Quantitative expression of C-type lectin receptors in humans and mice. Int J Mol Sci 2012;13:10113-31.

27 Goodnow CC. Multistep pathogenesis of autoimmune disease. Cell 2007;130:25-35

28 Allen CD, Ansel KM, Low C, et al. Germinal center dark and light zone organization is mediated by CXCR4 and CXCR5. Nat Immunol 2004;5:943-52.

29 Victora GD, Dominguez-Sola D, Holmes AB, et al. Identification of human germinal center light and dark zone cells and their relationship to human B-cell lymphomas. Blood 2012;120:2240-8.

30 Liu Z, Davidson A. Taming lupus - a new understanding of pathogenesis is leading to clinical advances. Nat Med 2012;18:871-82. 


\section{ARD}

Cathepsin S inhibition suppresses systemic lupus erythematosus and lupus nephritis because cathepsin S is essential for MHC class Il-mediated CD4 T cell and B cell priming

Khader Valli Rupanagudi, Onkar P Kulkarni, Julia Lichtnekert, Murthy Narayana Darisipudi, Shrikant R Mulay, Brigitte Schott, Sabine Gruner, Wolfgang Haap, Guido Hartmann and Hans-Joachim Anders

Ann Rheum Dis 2015 74: 452-463 originally published online December 3, 2013

doi: 10.1136/annrheumdis-2013-203717

Updated information and services can be found at:

http://ard.bmj.com/content/74/2/452

\section{These include:}

Supplementary Material

References

Email alerting service
Supplementary material can be found at:

http://ard.bmj.com/content/suppl/2013/12/03/annrheumdis-2013-2037 17.DC1

This article cites 30 articles, 7 of which you can access for free at: http://ard.bmj.com/content/74/2/452\#BIBL

Receive free email alerts when new articles cite this article. Sign up in the box at the top right corner of the online article.

Topic
Collections

Articles on similar topics can be found in the following collections

Immunology (including allergy) (5144)

Connective tissue disease (4253)

Systemic lupus erythematosus (571)

Renal medicine (204)

\section{Notes}

To request permissions go to:

http://group.bmj.com/group/rights-licensing/permissions

To order reprints go to:

http://journals.bmj.com/cgi/reprintform

To subscribe to BMJ go to:

http://group.bmj.com/subscribe/ 